\title{
Betwixt and Between: A Pilot Study Exploring the Experiences of Clinical Educators Teaching in a Dispersed Model of Entry-Level Physiotherapy
}

\section{Curriculum}

\author{
Sarah Barradell \\ La Trobe University, Australia \\ Felicity Blackstock \\ La Trobe University, Australia \\ Sally Mastwyk \\ La Trobe University, Australia \\ Clarice Y. Tang \\ La Trobe University, Australia \\ Joan Leo \\ La Trobe University, Australia \\ Janet McConville \\ La Trobe University, Australia
}

\begin{abstract}
Education of the future healthcare workforce has long been a partnership between university and healthcare sectors, with students learning under the shared guidance of academics and clinicians. Traditionally, academics have taught in the classroom and clinicians have engaged students at the patient bedside. Using a phenomenologically-oriented approach, this pilot project explored the experiences of clinicians who team-taught a theoretical subject in a classroom environment. Purposeful sampling of physiotherapy staff within a metropolitan healthcare organisation was used. Six clinicians were recruited and, prior to teaching, completed a blended educational program about higher education teaching and learning. The clinicians taught classes of twenty students within new classroom spaces co-located at the healthcare organisation, with curricula provided by the university. Two semi-structured interviews were conducted with each clinician at the beginning and end of the allocated teaching period. Transcripts from the semi-structured interviews were analysed and four themes emerged. First, physiotherapists initially identified as clinicians not teachers, but their perceptions later broadened. Second, the intention of teaching was patient-focused. Third, the balancing of multiple roles resulted in challenges for the clinicians; and fourth, the experience involved new immersion in digital media. This work explores a different form of educator role - likened to a pracademic - and supports the need for considered approaches to teaching and links between theory/education and practice to meet the demands of modern healthcare and university learning.
\end{abstract}

Keywords: clinical educator; health sciences; phenomenology; physiotherapy; pracacademic; practice-based education 
*Corresponding Author: Sarah Barradell, Physiotherapy, School of Allied Health, La Trobe University, VIC, Australia

Email: s.barradell@latrobe.edu.au

Journal URL: http://e-learning.coventry.ac.uk/ojs/index.php/pblh

Barradell, S., Blackstock, .F.C., Mastwyk, S., Tang, C.Y., Leo, J., and McConville, J. (2018) 'Betwixt and between: A pilot study exploring the experiences of clinical educators teaching in a dispersed model of entrylevel physiotherapy curriculum'. International Journal of Practice-based Learning in Health and Social Care, 6 (2), 80-94

\section{cc) (i) (5) $\Theta$}

BY NC ND (C) 2018 Sarah Barradell, Felicity Blackstock, Sally Mastwyk, Clarice Tang, Joan Leo, and Janet McConville. This Open Access article is distributed under the terms of the Creative Commons Attribution Attribution-Non-Commercial No Derivatives 4.0 International License

(https://creativecommons.org/licenses/by-nc-nd/4.0/ ), which permits unrestricted non-commercial use, distribution, and reproduction in any medium, provided the original work is properly cited and is unaltered. 


\section{Introduction}

Practice-based education is becoming a more established approach to teaching and learning in health professional courses as tertiary education shifts towards a greater vocational emphasis. This approach suggests that learning is usefully situated within practice-relevant contexts, involving but not limited to professional or clinical placements, as practice provides experiential learning opportunities (Higgs 2012, Higgs et al.1999, Kolb and Kolb 2012, Orrell et al. 1997). Health professional courses have long involved affiliations between universities and healthcare settings to provide this contextualised learning; learning of foundational knowledge /skills has traditionally occurred at university, followed by clinical and work-based placements in later years (Korthagen and Kessels 1999, Orrell et al. 1997, Tom 1997).

However, practice-based education recognises that learning to be a health professional is more than the addition of placement opportunities. As well as being attuned to the features of practice, practice-based education pays attention to the embodiment of practice; the context of time and place; the uncertainty and fluidity of practice; inter-professionality; and the social collaborative elements of practice (Boud 2012). One way to move towards this view of practicebased education is to consider the environment of the learning experiences, and in doing so, broaden and shift practice relationships in new directions.

A dispersed learning approach in entry-level healthcare programs may bring us closer to Boud's view of practice-based education. This approach distributes learning across various environments and personnel, involving clinicians and healthcare settings in potentially nontraditional ways with academic staff and universities. It provides an opportunity to strengthen industry and university partnerships; form new relationships between student, academic and clinician (McDaniel and Collaruli 1997); bridge theory and practice (Posner 2009); and cultivate new practice collaborations amongst involved parties.

The success of such an approach will be reliant on the engagement of those 'in practice' including clinicians - as it redefines long-established educator roles. Many health practitioners assume a clinical educator role in addition to their patient-oriented responsibilities (Öhman, Hägg, and Dahlgren 2005). That role typically involves supervision of small numbers of students working at the bedside (Öhman, Hägg, and Dahlgren 2005); the teaching is highly contextualised to client caseloads and specific work settings. There is often a tendency for clinicians to adopt an apprenticeship model (DeVita 2007, Kell and Jones 2007), with the student (apprentice) learning their craft through observation and mentorship from a qualified practitioner (Delany and Bragge 2009, DeVita 2007, Higgs and Hunt 1999). A dispersed model, however, disrupts traditional boundaries of theory and practice, and of learning and work, and the roles and experiences of educators may also change.

The experience of clinicians transitioning from practice to university environments suggests that teaching at the bedside may not be the same as teaching in a formal classroom. Health professionals joining academia report feelings of anxiety, uncertainty, and lack of confidence in their new role despite successful clinical careers (Anderson 2009, Hurst 2010, Murray, Stanley, and Wright 2014, Smith and Boyd 2012). Those who have transitioned see the process as a career change, requiring support and setting of realistic expectations around the capabilities that the new role necessitates (Smith and Higgs 2013). Yet less is known about the experiences of those in newly emerging roles - roles that may blur practice and academic boundaries although it is acknowledged that there is often considerable variation across such roles (Lathlean 2007, Stevenson, Chadwick, and Hunter 2004).

The aim of this study was to explore the lived experiences of practising clinicians with a clinical supervision role who undertook new academic-like responsibilities in a classroom setting. The responsibilities involved teaching into relocated non-practicum subjects once taught at university facilities by academic staff. In the remainder of this article, the background of the study and method is described. Four themes, supported by rich quotes from participating clinicians, are presented as findings, and implications for future practice are discussed. 
Although a pilot project in physiotherapy provides the context, the research has relevance to health professional education more broadly: those thinking about partnerships between universities and industry, how to bridge the theory-practice gap in new ways, and what to consider when widening these communities of practice.

\section{Method}

The research described in this article is a phenomenologically-oriented inquiry. Phenomenology is concerned with gaining an understanding of how a phenomenon is experienced and made sense of by a group of people (van Manen 1990). Our approach was to identify themes that richly described the lived experiences of physiotherapists undertaking new roles, to see the situation as they did.

\section{Context}

One of La Trobe University's Academic and Research Networks (ARN) was involved in this pilot. Academic and Research Networks are large metropolitan teaching healthcare networks consisting of acute, sub-acute and ambulatory care across multiple sites. The particular ARN was selected for the pilot as its infrastructure was most developed. The physical space for classes already existed on the primary healthcare site, and the organisational partnership between university and health network had been formally established over a decade earlier. The pilot involved a move from university-based teaching and learning of theoretical non-clinical physiotherapy subjects. Instead, two subjects were relocated to the classrooms based at the ARN sites and taught by clinicians who were employed by the healthcare provider. This article describes the analysis of the experience of the clinicians involved in teaching the classes at the new location.

\section{Participants}

Recruitment involved a form of purposeful sampling. A Team Leader employed by the healthcare provider identified and approached suitable participants who met the following inclusion criteria:

- Had supervised at least one entry-level physiotherapy student from La Trobe University in the clinical environment in 2014

- Agreed to facilitate one or more theory-based classroom learning experiences associated with the pilot project

- Participated voluntarily to the research project

Fourteen people were identified as meeting the inclusion criteria. Six clinicians (all women) agreed to be involved and signed consent forms. Table 1 contains demographic information of those who participated.

\section{Study Design}

The pilot comprised two theoretical subjects (units). The learning outcomes of both subjects were related to physiotherapy practice, although the subjects did not involve any clinical practicum experience. Complexity of practice in core clinical areas (being cardiorespiratory, neurological and musculoskeletal physiotherapy) was the focus of one subject. The other introduced students to two new areas of practice: paediatrics; and gender-specific concerns (e.g. incontinence and peri-partum care). The subjects ran concurrently across a five-week teaching period, although the final week did not involve scheduled classes. Each of the clinicians involved in the pilot taught into one of these two subjects. Two clinicians were involved in the paediatrics/gender-specific subject, and four in the complex clinical practice subject. The clinicians were responsible for teaching the curriculum and set-up of various teaching spaces. Subject coordination, development of curriculum, and assessment (marking 
and results) remained the responsibility of academic staff primarily based at the university campus. The minimum number of hours of classroom-based teaching for each clinician was four hours (range 4-21 hours).

The project was approved by the human ethics committees of both the university (FHEC14/010) and the healthcare provider (44-14). All participants gave written informed consent.

Table 1: Summary of demographic information of participants.

\begin{tabular}{|c|c|c|c|c|}
\hline Clinician & $\begin{array}{l}\text { Years } \\
\text { Clinical } \\
\text { Experience }\end{array}$ & $\begin{array}{l}\text { Years } \\
\text { Clinical } \\
\text { Educator }\end{array}$ & PD in T\&L & Previous Classroom T\&L \\
\hline A & $10+$ & $10+$ & $\begin{array}{l}\text { Yes } \\
\text { - Clinical educators course }\end{array}$ & $\begin{array}{l}\text { Yes } \\
\text { - UG (Other uni) } \\
\text { - PG/PD Courses }\end{array}$ \\
\hline B & $10+$ & $5-10$ & $\begin{array}{l}\text { Yes } \\
\text { - Clinical educators course } \\
\text { (5-10 hours ) }\end{array}$ & $\begin{array}{l}\text { Yes } \\
\text { - Lecturing UG (LTU) } \\
\text { - APA/PD Courses }\end{array}$ \\
\hline C & $10+$ & $5-10$ & No & No \\
\hline D & $5-10$ & $3-4$ & $\begin{array}{l}\text { Yes } \\
\text { - NHET Sim } \\
\text { - Clinical educators course } \\
\text { - APP training }\end{array}$ & $\begin{array}{l}\text { Yes } \\
\text { - PD Courses } \\
\text { - Tutor (1 month, other uni) }\end{array}$ \\
\hline$E$ & $10+$ & $10+$ & $\begin{array}{l}\text { Yes } \\
\text { - Clinical educators course }\end{array}$ & No \\
\hline $\mathrm{F}$ & $10+$ & $10+$ & $\begin{array}{l}\text { Yes } \\
\text { - Clinical educators course }\end{array}$ & No \\
\hline
\end{tabular}

UG = Undergraduate; $P G=$ Post-graduate; $A P A=$ Australian Physiotherapy Association; $P D=$ Professional Development; LTU = La Trobe University; NHET-Sim = National Health Education Training - Simulation; APP $=$ Assessment of Physiotherapy Practice

The participating clinicians were involved in a blended education program about higher education teaching and learning before the teaching period began. The purpose was to help orientate and familiarise participants with academic practices, both general (i.e. university level) and specific (contextual to pilot institution). This program comprised three elements. The first was an online module developed by physiotherapy academic staff, in consultation with educational designers. This module provided an overview of key higher education teaching and learning concepts, with application to the university's physiotherapy curriculum. Concepts included student-centred learning, enquiry-based learning, constructive alignment, giving feedback and reflective practice. All sections incorporated self-learning activities and scenarios. Clinicians had access to this module prior to, and for the duration of, their involvement in the project and could work at their own pace, returning to it as and when a situation might arise in class. The second element involved two teleconferences; clinicians joined at least one of these. This was an opportunity to discuss aspects of the online module; the scenarios presented in the online module were used to help frame discussions. The third element of the education program was a face-to-face session, bringing together the teaching teams of the two subjects involved in the pilot. The aim of this session was to discuss subject-level curriculum and administration. Additionally, clinicians were able to seek informal assistance and mentorship from academic staff members via telephone or email correspondence as required, both prior to and during the teaching period. Two people took up this opportunity: one sought email assistance to clarify a particular aspect of a class, and the other sought weekly mentoring. 


\section{Data collection}

In addition to the collection of demographic information, two individual semi-structured interviews were completed with all clinicians. The first was conducted after completion of the education program but before each clinician was involved in her first class. The subsequent interview took place when the clinician had concluded all of their teaching commitments - this was as close to the final class as was reasonably practicable. An interview schedule with suggested follow-up probes was used (Table 2). Two researchers conducted the interviews (SB and $\mathrm{JL}$ ) - the same researcher completed all interviews with a particular individual. Interviews lasted between 45 and 60 minutes. They were audiotaped, transcribed verbatim by qualified transcribers, and then de-identified.

Table 2: Summary of stems for the semi-structured interviews

\section{Prior to Teaching Experience}

Tell me about a situation from today (or the past week if did not work today) that stands out for you as typical of being a clinical educator?

How would you describe your role as a clinical educator?

You will be involved as a clinical educator in a different way this semester (i.e. teaching a theory-based subject). Can you describe what you expect of this role?

What sorts of attributes are required?

How do you feel about taking on this different role?

How would you describe your teaching style?

You have participated in training sessions in preparation for this different role. Describe a moment that stood out for you.

\section{Following Teaching Experience}

You have now started teaching for $<<$ subject name >>. Tell me about a moment that has stood out for you.

Tell me about an occasion where a student or group of students asked you for help in this subject.

Last time we talked about your role as a clinical educator (and you mentioned $\mathrm{x}$ ). How do you see your role now?

We also talked about the kinds of attributes needed to be a clinical educator (and you mentioned $\mathrm{x}$ ). How do you see this now?

How do you feel about the teaching that you have undertaken so far?

You participated in training sessions in preparation for this different role. Describe an occasion in your teaching where you used an aspect or aspects of that training.

Has your behaviour in clinical teaching changed at all? How?

\section{Data analysis}

Two researchers (SM and JM) independently analysed the data. The two transcripts from each clinician were analysed as one data set, as the researchers sought to understand the entire lived experience, from initial training to the end of classroom teaching. Data analysis was an iterative process that involved the researchers immersing themselves in the data by multiple rereadings of transcripts. All transcripts were first read to become familiar with each clinician's 
experiences overall. The audio recordings were utilised whenever clarification was needed. Each transcript was then carefully read again in its entirety and a list of initial codes, representing words or statements that seemed meaningful to the clinicians, was generated. The codes were collated into groups reflecting initial emerging themes or subthemes, and these were refined by identifying what was shared across the accounts. At this point, the two researchers met to bring together their codes and formulate the final themes through a consensus discussion. This discussion was supported by a third researcher (FB), who checked that the themes were consistent with the codes and data set. Table 3 provides an example of theme development. The final themes were forwarded to the clinicians for member checking no comments were received.

Table 3: Example of moving from initial coding to theme

\begin{tabular}{|c|c|c|c|}
\hline Transcript excerpt & Codes & Subtheme & Theme \\
\hline $\begin{array}{l}\text { 'I would no doubt learn } \\
\text { some things that would } \\
\text { improve my interaction } \\
\text { with the students, } \\
\text { however there is always } \\
\text { the side of it that we are } \\
\text { just so busy all the time } \\
\text { and that it is adding } \\
\text { extra work to us, you } \\
\text { know, that's just a reality } \\
\text { of the clinical situation.' }\end{array}$ & $\begin{array}{l}\text { New knowledge } \\
\text { and skills; juggling } \\
\text { roles; busy; time } \\
\text { poor; additional } \\
\text { work }\end{array}$ & Conflicting priorities & $\begin{array}{l}\text { Challenges were } \\
\text { experienced with } \\
\text { the balancing of } \\
\text { multiple roles }\end{array}$ \\
\hline
\end{tabular}

Researchers inevitably bring their own personal and academic biases to research. A brief description of the researchers' backgrounds are presented to enhance reflexivity (Johnson and Waterfield 2004). Both JM and SM are academic staff who were involved in the curriculum development of the two subjects taught in the pilot and have experience teaching the subjects in the classroom environment at the university. FB is an academic with curriculum design and teaching experience. Having no involvement in the subject curriculum or subject teaching, FB provided a more distant perspective. The use of three analysts enhanced the validity of the analysis through analyst triangulation (Patton 1999).

\section{Findings}

The findings of this research are presented as four themes. The first describes how the physiotherapists initially identified as clinicians not teachers, but how the experience expanded their perceptions of professionally oriented teaching and learning. The second reveals that the clinicians' teaching intention was patient-focused. The third explores the challenges of balancing multiple roles, and the fourth describes the experience of using digital media for teaching and learning. An account of each theme follows, supported by example quotes from the clinicians. T1 and T2 relate to the first or second interview respectively.

\section{Professional identity was broadened and transformation began}

Prior to the classroom experience, the clinicians saw themselves as practitioners, but not necessarily educators or teachers.

... I don't see myself as a teacher. I see myself as a physiotherapist. [Clinician C T1] 
Teaching, whether in the classroom or at the bedside, was primarily seen as an opportunity to transfer knowledge to novices. Knowing the answer and guiding students to a correct solution were considered essential teaching skills in either environment.

So l've got a fountain of knowledge and l've been trying to, you know, give my fountain of knowledge to - to people <laughs>. [Clinician A - T1]

The clinicians described the relationship between teacher and learner as important, yet they focused on the teacher's role in keeping the students interested in learning. They considered it was the teacher's responsibility to direct learning, with little reference to student ownership and agency. Maintaining student engagement was a source of anxiety for the clinicians.

If things aren't going to plan, so if people aren't - I think the main one is if people aren't engaged and are doing other things and, yeah, not focused on the task, I think personally I'll find it really hard to bring them back to task. [Clinician B - T1]

However, by the conclusion of the teaching period the clinicians' perceptions of being an educator/teacher had begun to change and broaden. The way clinicians interacted with students changed as a result, encouraging student reflection, self-directed learning and questioning for clarification.

So letting them work and find out themselves and not just giving them the answer straight away, that was totally new for me... Like I might be "Yeah what do you think, what do you think?" but they were really - they were owning it more.

[Clinician B - T2]

The clinicians were also thinking about how they might make changes to their practice in other contexts.

I want to try and get some more of that PBL [problem-based learning] and reflective practice and all of that stuff, I want to try and put that into my clinical education. [Clinician B - T2]

\section{Intention of teaching was patient-focused}

The clinicians' intentions were focused on providing quality patient care; that is, students were there to learn so they could provide better healthcare to patients, and the clinicians saw it as their responsibility to ensure that happened.

What I would like to get across to students is looking at [patient] assessment particularly, and really honing in on their observation skills... So that's kind of, you know, my goal for them. [Clinician F - T1]

The clinicians' focus on patient care was so strong that at times they confused patients and students in describing their lived experience.

[How would you describe your role as a clinical educator?] It probably varies a bit depending on the patient, sorry, the student experience... [Clinician E - T1]

The clinicians' own clinical practice was a driver for their teaching. This was also an issue for some who wanted to change the curriculum or adapt activities to include specific knowledge and skills that they considered important and relevant at their workplace.

I definitely like control. So I guess it is hard to... to do it when someone else has set... set the question and the information and the stuff for you, because there were things that I would've included in... in the session which I did end up adding... [Clinician E - T2] 
For the first contact practitioner some of the assessment and treatment techniques... it's more the exercises [that the students suggested] would be too difficult for a lot of patients seen in clinical practice. So I did highlight that... I know the bits I would do differently but I said to the students "no I am not going to confuse you"... [Clinician A - T2]

\section{The challenge of balancing the different roles of learner, educator and clinician}

The clinicians' accounts demonstrated a juggling of different roles: continuing their caseload, learning a new field, and teaching a new subject. These combined roles were time-consuming, leading to longer work hours and conflicting priorities between patient care and classroom teaching. The clinicians felt they underestimated the time required for preparation to conduct the class and to set up the teaching environment amidst their clinical obligations. In the beginning, preparation was seen as a straightforward process of obtaining a tutor's guide, reading it and then teaching the class through transfer of expert knowledge.

I'm in a good position to use a lot of my clinical knowledge and anecdotes and experience but still having all that information [tutors' guides] that's required from the teaching school. [Clinician F - T1]

Some clinicians did not anticipate the time and the need to develop their own knowledge and skills in higher education teaching.

The pre-learning package was a bit more work than what I expected... I didn't know there was any component of learning for myself... [Clinician B - T2]

The clinicians tended to alter their daily schedule to ensure all roles were addressed to their satisfaction and ensure patient care was not impacted.

... I'd often find myself coming in at quarter to eight, going straight to [the ward], treating the patient, coming upstairs, getting my list, then going to do the teaching and then going straight back to treating again. And so that sometimes that got a little bit stressful... [Clinician D - T2]

The set-up of teaching spaces was an additional commitment. The clinicians felt that issues with these spaces detracted from the learning experience for students (i.e. when the environment could not be ideally configured for how they had planned particular activities). For those not working on the specific healthcare site, moving from their workplace to the classroom - and taking equipment with them - was another burden.

I had an active exercise class which requires all of them [students] moving around and there was no space... I didn't feel that I was achieving the experience for the students that I would have liked to have given them if they were actually participants in a class. [Clinician C - T2]

The clinicians described feeling relieved when the teaching period had finished. They could return to their primary clinical role and there was no longer the need to juggle multiple demands. Despite the challenge and relief, they also felt that they had met all obligations and the overall experience was positive. All but one of the clinicians expressed an interest in teaching again should future opportunities arise.

I really enjoyed it actually, I think it was a tough week having clinical responsibilities and teaching responsibilities and having to ensure that everything was set up and packed up each day. It was a challenging week and by the Friday afternoon I was absolutely exhausted, I was so happy the week was over. But after each session I kind of came out of it going oh yeah that was really good, like I feel like you know it was an effective session, the students have learnt. [Clinician D - T2] 


\section{Immersion in digital age for teaching and learning}

Engaging with digital technologies for teaching and learning purposes created anxiety for the clinicians. The online environment was not considered part of a physiotherapist's routine workspace.
... it was the bit about the online access, the Facebooking or the texting... we don't think about accessing those things in work time because it's work time... and you don't do those things in the work environment... then for me to think about it from a student point of view... that when they're in class with us that is their work environment, if they're online it's for research or for whatever the task is that they've got that they're doing in class. [Clinician C - T1]

The clinicians were also worried about how digital media might impact student engagement and the relationship between teacher and learner. How students might use technology differed from the clinicians' own past learning experiences and challenged their ability to relate to students.

So I'm not sure how well I handled the whole, you know, students being on laptops. It was hard to know if they were looking things up for their group or if they were doing something else. That was probably something in the whole session that I wasn't quite sure of... [Clinician F - T2]

The clinicians also expressed concern about the technology failing during class, with subsequent disruption to class-based activities. Access to the online learning system was sometimes not possible, due to hospital firewalls, for example, or because a limited number of computers was available for staff to access during work hours, or because the audio-visual equipment occasionally did not function correctly.

That [class] was an absolute nightmare; [the] Media Player wouldn't work and we got - we tested it all out beforehand and it didn't work... it took at least a week to get sorted and in the end we had to hire the laptop and data projector even though there's facilities in that room, because they just couldn't sort out Media Player, and then the stress of making sure that was there in the morning. So just all those logistical things, they were the worst part of it. [Clinician B - T2]

Clinicians wanted someone with experience in using the computers, data projectors and online learning environment to support them in the classroom in real time, suggesting low self-efficacy with technology use. At the time of the pilot this was not possible, which created some uneasiness.

$\ldots$ and if there was a problem at $X$ site with the AV [audio-visual] there was no one on call to come and help, which made it difficult, whereas at the $Y$ site, if there was a problem you'd just go out and get [the technician] to come in and she'd fix whatever it was so that was good. [Clinician C - T2]

\section{Discussion and implications for teaching practice}

This study adds to knowledge about the lived experience of health professionals transitioning to new educator-oriented roles. The emergent themes support the notion that transition from clinical work (including clinical education) to other teaching roles is challenging and requires support (Murray, Stanley, and Wright 2014, van Lankveld et al. 2017). Existing literature has primarily explored the transition from clinician to clinical educator (e.g. Delany and Bragge 2009), clinician to academic (e.g. Duffy 2013), and clinician to lecturer practitioner (and practice educator role) (e.g. Nelson and McSherry 2002). The role of the clinicians in this pilot shares most similarities with the lecturer practitioner / practice educator, especially in terms of (i) providing a visible link between theory/education and practice, and (ii) dual responsibilities in clinical and academic settings. In this way, these roles are a form of pracademic (Posner 2009) 
lying at the nexus of academia and practice (which potentially include research and policy). However, a significant difference for participants in this study related to their employment. Generally, lecturer practitioners and practice educators are defined positions employed within organisations, with clearly articulated position descriptions, roles and responsibilities, and performance expectations. The employment status, including role, title and remuneration, of the clinicians involved in our pilot remained unchanged (i.e. employed by the healthcare site). This may have contributed to the perception of a 'disrupted' role, where the classroom teaching and related activities were at times seen as a burden for the clinicians.

When invited to reflect on their 'part and place' in teaching, the clinicians in this study reported being physiotherapists rather than educators, transferring their clinical expertise and knowledge to students. This transmission-oriented and teacher-centred approach is historically situated in physiotherapy education (Delany and Bragge 2009, Kell and Jones 2007), and therefore this finding is not surprising. However, in the study by Kell and Jones (2007), experienced physiotherapy clinicians (11 or more years of clinical educator experience) were more likely to adopt a facilitatory approach to clinical education. In this pilot, clinicians did begin to recognise and adopt other teaching approaches as time went on, reinforcing the findings of Kell and Jones (2007), that with experience, changes to approach to teaching occur. Despite having limited previous formal schooling in higher education theory, select teaching experiences supplemented by a short tailored blended course were sufficient to start to shift clinicians' perspectives of teaching; these new perspectives might then transfer to other areas of their work. A relatively small investment of resources has the potential to transform teaching practice - with a potential impact on clinical practice too - although the longer-term sustainability is not known.

Challenges when transitioning from health professional to new educator roles are common, with the clinicians of this pilot describing many examples previously reported elsewhere in the literature, including establishing credibility with students, fear of lack of student engagement in the classroom, managing large class sizes, and working with digital media (Anderson 2009, Murray, Stanley, and Wright 2014, Warner 2015). Balancing competing demands was perhaps the most significant challenge; this has been reported in other studies (Delany and Bragge 2009, Duffy 2013, Nelson and McSheery 2002). The clinicians of this pilot underestimated preparation time and their own learning needs. With the teaching co-located at a healthcare site rather than university campus, clinicians faced additional challenges. They often had to move between clinical site and teaching space, at times taking considerable equipment with them, and in some instances further time was required to set up. These logistical issues would need to be addressed for these roles and models of education to be sustainable in the long-term.

The findings of this study further support the need to consider organisational factors (systems and culture) to improve both the outcomes for learners and the experience for clinicians, and to ensure sustainability of such an educational model. Current literature clearly suggests that support from peers in a community of practice is essential for successful transition to academia (Murray, Stanley, and Wright 2014, Nelson and McSherry 2002, Rees 2017, Smith and Boyd 2012, van Lankveld et al. 2017). This was borne out in this pilot too, although support was offered to the participating clinicians in limited ways (i.e. preliminary blended online program and subsequent ad hoc assistance offered remotely). This approach did not easily facilitate peer exchange or role modelling from more experienced academics. The clinicians were not released from their usual clinical responsibilities, and this increased the need for support with added difficulties in time management. Allowing clinicians time to step away from their clinical duties and focus on new roles may decrease the sense of being overwhelmed and allow necessary time for all demands, including professional development for being a pracademic. The positive experiences that come from teaching the profession's future workforce (Öhman, Hägg, and Dahlgren 2005) are likely to make such an investment worthwhile. Given reports of the benefits afforded by timely access to resources, which includes mentors, further consideration into how we support the professional development of clinicians to undertake more wide-ranging educational roles appears to be needed. This might (i) help clinicians to view being an educator 
in more expansive ways, (ii) reduce potential anxiety associated with being an educator, and (iii) improve outcomes for learners and educators alike.

This study was a pilot involving one healthcare site, two university subjects and six participants. This may be considered a limitation in the research, as it is unclear whether the experiences of these participants would be shared by those at different healthcare provider sites or if more participants were involved. However, all clinical educators involved in the experience consented to participate and therefore the sample represents the total available for recruitment. Another potential limitation is that participating clinicians had no control or involvement in curriculum development and student assessment, meaning that they were involved in only some aspects of university curriculum, teaching and learning. However, being a pilot project, there was limited resourcing and the aim of the study was directed at experiences associated with the classroom.

\section{Conclusions}

The aim of this article was to explore how qualified physiotherapists experienced the transition to a 'pracademic'-type role. Contemporary healthcare practice necessitates better links between theory and practice, and there is enormous potential in involving practitioners in entry-level health professional education in new ways. The findings from this pilot demonstrate that any assumption that clinicians with extensive clinical education experience at the patient's bedside can easily transfer their skills to fulfil the role of an educator in a classroom is unfounded. Teaching in an academic environment requires different capabilities to teaching clinically. Investment of time and resources are essential to successful outcomes for both staff and students. The connections between theory/education and practice should extend to all parties in university and industry as organisational culture and systems play a larger role in success than might be anticipated. It is also valuable to consider many potential levels of collaboration that extend beyond teaching, to include other areas of academic life.

\section{Acknowledgements}

Thank you to Alfred Health, Victoria who were involved in this pilot. 


\section{References}

Anderson, J.K. (2009) 'The work role transition of expert clinician to novice academic educator'. Journal of Nursing Education, 48 (4), 203-208 https://doi.org/10.3928/0148483420090401-02

Boud, D. (2012) 'Problematising practice-based education'. in Practice-Based Education Perspectives and Strategies. ed. by Higgs, J., Barnett, R., Billett, S., Hutchings, M., and Trede, F. Rotterdam, Netherlands: Sense pp. 55-70

Delany, C. and Bragge, P. (2009) 'A study of physiotherapy students' and clinical educators' perceptions of learning and teaching'. Medical Teacher, 31 (9), e402-e411 https://doi.org/10.1080/01421590902832970

DeVita, M.A. (2007) 'Simulation and the prognosis for the apprenticeship model of health care education'. Journal of Intensive Care Medicine, 22 (5), 310-311 https://doi.org/10.1177/0885066607304435

Duffy, R. (2013) 'Nurse to educator? Academic roles and the formation of personal academic identities'. Nurse Education Today, 33 (6), 620-624 https://doi.org/10.1016/j.nedt.2012.07.020

Higgs, J. (2012) 'Practice-based education: The practice-education-context-quality nexus'. in Practice-Based Education Perspectives and Strategies. ed. by Higgs, J., Barnett, R., Billett, S., Hutchings, M., and Trede, F. Rotterdam, Netherlands: Sense, 3-12

Higgs, J. and Hunt, A. (1999) 'Rethinking the beginning practitioner introducing the "interactional professional"'. in Educating Beginning Practitioners: Challenges for Health Professional Education. ed. by Higgs, J., and Edwards, H. Oxford: Butterworth-Heinemann, 10-18

Higgs, J., Hunt, A., Higgs, C., and Neubauer, D. (1999) 'Physiotherapy education in the changing international healthcare and educational contexts'. Advances in Physiotherapy, 1 (1), 17-26 https://doi.org/10.1080/140381999443528

Hurst, K.M. (2010) 'Experiences of new physiotherapy lecturers making the shift from clinical practice into academia'. Physiotherapy, 96 (3), 240-247 https://doi.org/10.1016/i.physio.2009.11.009

Johnson, R. and Waterfield, J. (2004). 'Making words count: The value of qualitative research'. Physiotherapy Research International, 9 (3), 121-131 https://doi.org/10.1002/pri.312

Kell, C. and Jones, L. (2007) 'Mapping placement educators' conceptions of teaching'. Physiotherapy, 93 (4), 273-282 https://doi.org/10.1016/i.physio.2006.11.011

Kolb, A.Y. and Kolb, D.A. (2012) 'Experiential learning theory'. in Encyclopedia of the Sciences of Learning. ed. by Seele, N.M. Boston, MA: Springer, 1215-1219

Korthagen, F.A.J. and Kessels, J.P.A.M. (1999) 'Linking theory and practice: Changing the pedagogy of teacher education'. Educational Researcher, 28 (4), 4-17 https://doi.org/10.3102/0013189X028004004

Lathlean, J. (2007) 'Researching the implementation of pioneering roles in nursing and midwifery. Empirical Insights about lecturer practitioners, consultant nurses and nurse registrars'. Journal of Research in Nursing, 12 (1), 29-39 https://doi.org/10.1177/1744987106073582 
McDaniel, E.A. and Colarulli, G.C. (1997) 'Collaborative teaching in the face of productivity concerns: The Dispersed Team Model'. Innovative Higher Education, 22 (1), 19-36 https://doi.org/10.1023/A:1025147408455

Murray, C., Stanley, M., and Wright, S. (2014) 'The transition from clinician to academic in nursing and allied health: A qualitative meta-synthesis'. Nurse Education Today, 34 (3), 389-395 https://doi.org/10.1016/j.nedt.2013.06.010

Nelson, L. and McSherry, R.G.N. (2002) 'Exploring the lecturer/practitioner role: Individuals perceptions of the lived experience'. Nurse Education in Practice, 2 (2), 109-118 https://doi.org/10.1054/nepr.2002.0061

Öhman, A., Hägg, K., and Dahlgren, L. (2005) 'A stimulating, practice-based job facing increased stress - Clinical supervisors' perceptions of professional role, physiotherapy education and the status of the profession'. Advances in Physiotherapy, 7 (3), 114-122 https://doi.org/10.1080/14038190510010359

Orrell, J., Gonda, J., Longson, D., and Edgecombe, K. (1997) 'Making it all count'. (Paper presented at the Higher Education Research \& Development Society of Australia Advancing International Perspectives Conference, Adelaide, Australia

Patton, M.Q. (1999) 'Enhancing the quality and credibility of qualitative analysis'. Health Services Research, 34 (5 Part 2), 1189-1208

Posner, P.L. (2009) 'The pracademic: An agenda for re-engaging practitioners and academics'. Public Budgeting \& Finance. 29 (1), 12-26 https://doi.org/10.1111/j.15405850.2009.00921.x

Rees, C.E. (2017) 'Short report: Transitions in health professional education: Theory, research and practice'. Focus on Health Professional Education: A Multi-disciplinary Journal, 18 (3), 4-9 https://doi.org/10.11157/fohpe.v18i3.244

Smith, C. and Boyd, P. (2012) 'Becoming an academic: The reconstruction of identity by recently appointed lecturers in nursing, midwifery and the allied health professions'. Innovations in Education and Teaching International, 49 (1), 63-72 https://doi.org/10.1080/14703297.2012.647784

Smith, M. and Higgs, J. (2013) 'Health professionals becoming university teachers'. in Educating Health Professionals: Becoming a University Teacher. ed. by Loftus, S., Gerzina, T., Higgs, J., Smith, M., and Duffy, E. Rotterdam: Sense, 15-22

Stevenson, K., Chadwick, A.V., and Hunter, S.M. (2004) 'National survey of lecturer/practitioners in physiotherapy'. Physiotherapy, 90 (3), 139-144 https://doi.org/10.1016/i.physio.2004.01.003

Tom, A.R. (1997) Redesigning Teacher Education. Albany, NY: SUNY Press

van Lankveld, T., Schoonenboom, J., Volman, M., Croiset, G., and Beishuizen, J. (2017) 'Developing a teacher identity in the university context: A systematic review of the literature'. Higher Education Research \& Development, 36 (2), 325-342 https://doi.org/10.1080/07294360.2016.1208154

van Manen, M. (1990) Researching Lived Experience: Human Science for an Action Sensitive Pedagogy. Albany, NY: SUNY Press 
Warner, M.L. (2015) 'From clinical practice to academia'. The Journal of Physician Assistant Education, 26 (2), 109-110 https://doi.org/10.1097/JPA.0000000000000019 